\title{
Psychological defenses and psychiatric symptoms in adults with pediatric spinal cord injuries
}

\author{
P Sammallahti, M Kannisto and V Aalberg \\ University of Helsinki, Department of Psychiatry, Tukholmankatu 8 C, SF-00290 Helsinki, Finland
}

\begin{abstract}
The psychological defenses and psychiatric morbidity of 30 adults with pediatric spinal cord injury and of 235 community controls were compared several years after the occurence of the injury. The patient group did not report more symptoms when measured with the Symptom Checklist-90 than the control group, but there were some characteristic features in their use of defenses as measured with the Defense Style Questionnaire. The adaptation process seems to follow a pattern: the greater the length of time since the injury, the less likely were the immature defenses omnipotence-devaluation and regression and the higher were the scores on the mature defense anticipation. It appears that the same result-symptom free adaptation-is first achieved by more immature means but as the adaptation process evolves, the psychological equilibrium can be maintained by mature defenses which do not distort reality. Furthermore, the results that patients with pediatric spinal cord injury scored higher on fantasy (daydreaming) and passive aggression (silent resistance) suggest that being injured very young may leave some faint, yet permanent psychodynamic traces.
\end{abstract}

Keywords: spinal cord injury; pediatric spinal cord injury; psychological defenses; psychiatric morbidity

\section{Introduction}

Previous research suggests that people adapt remarkably well even to such an extremely taxing trauma as spinal cord injury. Psychiatric morbidity seems rare after the first year. ${ }^{1,2}$ Less is known about the adaptation of subjects who have sustained spinal cord injury in childhood.

In clinical literature the adjustment process is usually described as a sequence of stages which have to be worked through in order to achieve psychosocial adjustment. The stages include psychological reactions similar to other situations of severe loss; most descriptive models include the stages of shocked denial, rage and anger, depression and, eventually, acceptance. Empirical studies provide mixed support for the stage theory. Although the reactions of denial, anger and depression are often found immediately postdischarge, there does not seem to be any empirical validation of the assumption that good adaptation is preceded by all the above stages. ${ }^{3}$ The finding of Richards ${ }^{4}$ that those who are least depressed tend to function best during rehabilitation and following discharge is illustrative.

The purpose of our study was to examine adaptation to pediatric spinal cord injury (SCI) within a psychoanalytic framework. Assuming that persons

Correspondence: Dr Veikko Aalberg with SCI do eventually perceive their lives to be as satisfying as people in general do, as has been suggested by previous research - what does it take to achieve this in terms of the crucial adaptive functions of the ego, the defense resources?

Psychological defenses can be conceived as a hierarchy, from immature via intermediate to mature defenses. Immature defenses - like projection - effectively displace the source of anxiety from oneself to others, but distort one's view of outer reality. Reaction-formation - an intermediate defense turns the anxiety-provoking impulse - for example covert hostility - into overt friendliness, but at the cost of distorting one's view of oneself, the inner reality. Mature defences - like anticipation - allow the anxiety-provoking situation to enter the awareness but work on it. ${ }^{5}$

Good adaptation is usually marked by mature defensive functions, but does this hold true when one has to face unusually demanding adaptation tasks? Possibly some distortion of reality is necessary to protect the ego from being overwhelmed by the extent of the injury. Traditionally, denial has been considered to play a positive role in the early stages of trauma, whereas in later stages, and certainly during rehabilitation, denial of the fact of the injury interferes with rehabilitative progress. ${ }^{6,7}$ On the other hand, Trieshmann $^{8}$ has challenged this view in her highly influential writings and states that despite much speculation, empirical findings do not support the 
idea of 'denial'. As for other ego defenses, there is virtually no empirical data on them in connection with adaptation to SCI.

The crucial questions of the present study were: do adults with pediatric SCI show psychiatric symptoms? Do they use the same kind of psychological defenses as people in general? Are the possible symptoms and defenses influenced by age at trauma, time since injury or the severity of the injury?

\section{Material and methods}

The study group comprised 23 males and seven females who had sustained SCI in childhood. The mean age was 32 (SD 10.3, range 19-64). The mean age at injury was 11 years (SD 5.3). 19 subjects had complete and four incomplete paraplegia, two subjects had complete and five incomplete tetraplegia. The subjects were collected from the central register of the Finnish National Organization for Disabled People and the patient databases of the Käpylä Rehabilitation Center in Helsinki and the Children's Hospital of the University of Helsinki. The catchment area of these institutions comprises approximately 5 million inhabitants. Of the 66 persons who were contacted, 47 assented to participate. Based on an inquiry concerning the type of injury, 11 persons were excluded because of insufficient severity of the SCI, or doubtful nature of the neurological lesion (eg, meningomyelocele were excluded) $(n=3)$; poor cooperation because of mental deficiency $(n=1)$; reluctance to travel or to participate in examinations in a hospital $(n=6)$; also, one person died before the examinations. Two of the excluded subjects were women $(19 \%)$. Eventually 36 subjects participated in the health study, which meant spending two days in the Käpylä Rehabilitation Center and included interviews and clinical examinations. Two males and four women participated in the interviews and the medical examinations but did not return the questionnaires used in the present study (mean age 38.4 , range $24-42$, mean age at injury 12.8 ). Based on the interview material, one of them fared poorly, the others well.

The control group was drawn from a group of 337 subjects from the general population. They were volunteers who consented to participate as controls and returned the questionnaires sent to a random sample of city employees, the participation rate being $56.2 \%$. The 337 volunteers were screened for psychiatric disturbance using the General Health Questionnaire ${ }^{9}$ with a cut-off score of 5; eventually 235 subjects were left to serve as healthy controls $(59 \%$ women, mean age 37 , SD 11 , range $18-64)$.

All the subjects completed two self-report inventories, the SCL-90 Symptom Checklist ${ }^{10}$ and the DSQ Defense Style Questionnaire. ${ }^{11}$ SCL-90 is a 90-item general psychopathology inventory that is answered according to a Likert format and yields scores on nine dimensions (somatization, obsessive-compulsiveness, depression, anxiety, hostility, phobic anxiety, paranoid ideation and psychoticism), in addition to a global score, the general severity index (GSI). It is an established inventory with good reliability (internal consistency consistently above 0.80). The Defense Style Questionnaire (DSQ) contains 88 items intended to assess the conscious derivatives of 25 defense mechanisms grouped into four categories: mature, neurotic, borderline and immature defenses. Each item is rated on a 9-point Likert scale. The defenses are scored by taking the mean score of the representative items. The maturity of defensive functioning as measured by the DSQ has been found to correlate with ego maturity and various measures of mental health. ${ }^{12}$

\section{Results}

No significant differences were found between persons with SCI and the able-bodied controls for any of the SCL-90 symptom subscales or the general severity index.

The defense score means and standard deviations for the study groups are displayed in Table 1. The pattern of defenses associated with the two groups differed significantly according to discriminant function analysis, $\mathrm{F}(25,236)=1.904, \quad P=0.007$. The univariate $F$ tests included in the discriminant function analysis for the separate defenses indicated that fantasy contributed most $(\mathrm{F}(1,260)=13.70$, $P=0.000)$ and passive aggression also significantly $(\mathrm{F} 1,260)=7.55, P=0.006)$, to the discriminant function. The contribution of task orientation was significant at the $P=0.03$ level $(\mathrm{F}(1,260)=4.70$, $P=0.03$ ). Because the subject and control groups differed in age and gender distribution the associations between age, gender and the three defenses - fantasy, passive aggression, and task orientation - were examined. In the group of 235 community controls the Pearson correlations between age/fantasy, and age/ passive aggression were nonsignificant, $r=-0.07$ and $r=-0.04$, respectively. The defense named task orientation, however, correlated significantly with age, $r=0.2, P=0.002$. A covariance analysis with age as covariate indicated that task orientation did not differentiate significantly between the subject groups $(P=0.08)$. According to $t$ tests, there were no significant gender differences in the use of fantasy $(\mathrm{T}=-0.447, \quad \mathrm{df}=231, \quad P=0.65), \quad$ passive aggression $(\mathrm{T}=-1.74, \quad \mathrm{df}=233, \quad P=0.08)$, or task orientation $(\mathrm{T}=0.656, \mathrm{df}=233, P=0.51)$. The correlation between age at injury and defense score was calculated in order to examine whether age at injury affects defense usage. The younger SCI subjects were when injured, the more likely they were to use projective identification $(r=-0.37, \quad P=0.04), \quad$ idealization $\quad(r=-0.45$, $P=0.01)$ and anticipation $(r=-0.42, P=0.02) .14$ of the subjects were injured before the age of 12 and 16 were older when injured. The group injured before puberty scored higher on idealization (the significance 
Table 1 Defense style and individual defense score means of adults with pediatric spine injury and healthy controls

\begin{tabular}{|c|c|c|c|c|}
\hline \multirow{2}{*}{$\frac{\text { Defense style/defense }}{\text { Mature defense style }}$} & \multicolumn{2}{|c|}{$\begin{array}{c}S C I \text { group } \\
\mathrm{n}=30 \\
\text { mean }(S D)\end{array}$} & \multicolumn{2}{|c|}{$\begin{array}{c}\text { Control group } \\
\mathrm{n}=235 \\
\text { mean (SD) }\end{array}$} \\
\hline & 5.9 & $(1.0$ & 6.2 & $(1.4)$ \\
\hline Task orientation & 5.7 & $(1.5)$ & 6.4 & $(1.7)$ \\
\hline Sublimation & 4.7 & $(2.2)$ & 5.7 & $(2.6)$ \\
\hline Humor & 6.9 & $(1.1)$ & 6.6 & $(1.5)$ \\
\hline Suppression & 5.0 & $(2.2)$ & 5.4 & $(1.8)$ \\
\hline Anticipation & 6.1 & $(1.7)$ & 5.9 & $(1.8)$ \\
\hline Affiliation & 4.8 & $(1.8)$ & 4.8 & $(2.0)$ \\
\hline $\begin{array}{l}\text { Neurotic defense } \\
\text { style }\end{array}$ & 3.6 & $(0.9)$ & 3.8 & $(1.3)$ \\
\hline Reaction formation & 3.9 & $(1.3)$ & 4.2 & $(1.5)$ \\
\hline Undoing & 3.4 & $(1.2)$ & 3.4 & $(1.6)$ \\
\hline Pseudoaltruism & 5.7 & $(2.1)$ & 5.7 & $(2.3)$ \\
\hline $\begin{array}{l}\text { Borderline defense } \\
\text { style }\end{array}$ & 3.5 & $(0.9)$ & 3.1 & $(1.1)$ \\
\hline $\begin{array}{l}\text { Omnipotence devalua- } \\
\text { tion }\end{array}$ & 3.3 & $(1.3)$ & 2.8 & $(1.4)$ \\
\hline Isolation & 4.1 & $(1.5)$ & 3.5 & $(1.5)$ \\
\hline Split & 3.8 & $(1.7)$ & 3.4 & (1.7) \\
\hline Denial & 2.8 & $(1.4)$ & 2.6 & $(1.1)$ \\
\hline Idealization & 3.5 & $(2.1)$ & 3.3 & $(2.2)$ \\
\hline Projective identification & 2.5 & $(2.8)$ & 2.5 & $(2.0)$ \\
\hline Immature defense style & 3.3 & $(0.8)$ & 3.1 & $(0.9)$ \\
\hline Consumption & 2.6 & $(1.2)$ & 2.9 & $(1.5)$ \\
\hline Inhibition & 3.2 & $(1.3)$ & 3.5 & $(1.5)$ \\
\hline Projection & 2.3 & $(0.9)$ & 2.0 & $(0.9)$ \\
\hline Passive aggression & 4.1 & $(1.0)$ & 3.5 & $(1.1)^{*}$ \\
\hline Acting out & 4.4 & (1.4) & 4.3 & $(1.4)$ \\
\hline Hypochondriasis & 2.9 & $(1.3)$ & 2.8 & $(1.6)$ \\
\hline Fantasy & 4.3 & $(2.5)$ & 2.7 & $(2.1)^{* *}$ \\
\hline Regression & 3.0 & $(1.3)$ & 3.2 & (1.6) \\
\hline Somatization & 2.5 & $(1.8)$ & 3.0 & (1.9) \\
\hline Withdrawal & 5.2 & (1.9) & 5.0 & $(2.0)$ \\
\hline
\end{tabular}

Significance of the contribution of the defense to the discriminant function; ${ }^{*} P=0.006 ;{ }^{*} P=0.000$

was low) and anticipation. The mean scores and standard deviations for idealization were: 4.4 (2.6) for the group injured before puberty and 2.8 (1.3) for those injured after puberty $(P=0.05)$. The scores for anticipation were $7.1(1.1)$ for the pre-puberty group and $5.3(1.8)$ for the post-puberty group $(P=0.005)$.

The correlation between time elapsed since injury and defense usage was as follows: the greater the length of time that had elapsed since the injury, the more the subjects used anticipation $(r=0.44, P=0.01)$, and the less regression $(r=-0.34, P=0.05)$ and omnipotence-devaluation $(r=-0.35, \quad P=0.05)$. To control for the possibility that the observed timerelated changes were due to normal development, the age-relatedness of these defenses was examined in the control group also (non-significant).

The severity of the injury was evaluated for the subjects with complete paraplegia or tetraplegia. The less severely injured were more likely to use task orientation $(P=0.44, P<0.05)$.

\section{Discussion}

The result that children with pediatric spinal injury grow up to be psychologically as well adjusted as people in general is consistent with previous research on the psychiatric morbidity of persons with SCI. When the result of the present study is compared with previous reports, it seems that persons with pediatric SCI fare better than persons injured in adulthood, which is in accordance with the finding of Mehnert ${ }^{13}$ that psychosocial adaptation is related to the age at which the disabling condition occurs; those with disabling conditions acquired before 20 years of age were bound to express greater well-being than those whose disabilities were acquired later. As has been found in other studies, ${ }^{14,15}$ the level of the injury does not appear to alter adjustment significantly.

It seems, however, that beyond the immediate level of symptoms, the adaptation process continues for much longer than just a couple of years and it appears that being injured very young leaves some faint, yet permanent psychodynamic traces.

The adaptation process seems to follow a pattern: first fairly immature but powerful defenses are required, later mature defenses with no realitydistorting qualities will suffice. The ambivalent extremes - regression and omnipotence - subside with time; instead one learns to anticipate what situations will probably provoke anxiety and prepares oneself in advance, which helps considerably.

Does it make a difference whether the injury takes place in early childhood or later, in adolescence? Though far from conclusive, the results suggest that if one is injured very young, idealization and projective identification tend to persist as defense mechanisms. In idealization, another person is thought to be incapable of doing wrong, and projective identification (as measured by the DSQ-items) means that another person is believed to have a hold on one's feelings. Elevated scores on these defenses suggest that being injured very young and being unusually dependent on parents can impair the shaping of an independent nondiffused identity. Characteristic of an independent identity is that others are perceived as neither saints nor villains and that there is a clear distinction between what I feel and what others experience.

The most important findings of this study relate to differences in the psychological defenses of the study groups. Two characteristic features in the defense pattern of pediatric SCI persons differentiated them from able-bodied controls: they scored higher on passive aggression and fantasy than the controls. As the use of these defenses was not related to time since injury, these characteristics do not seem to be a part of the adaptation process but represent more permanent shifts in the psychodynamic constellation of adult persons with pediatric SCI. The result seems to suggest that adults with pediatric SCI tend to convey aggressions by a psychological paralysis (passive aggression refers to silent resistance and roundabout 
ways of irritating others), and are prone to seek gratification in fantasy daydreams instead of real life (fantasy).

One interpretation of this finding could be that in order to master anxiety the subjects have made a definite change in their defensive strategy from active to passive. Immature as these means may be considered in normal development, they can be highly adaptive in circumstances in which more immediate routes of impulse outlet, be they aggression or sexual needs, are barred. A less benign interpretation is that the relatively dependent position during adolescence tends to foster indirect means of expressing needs that might confuse ones' surroundings.

There are two main caveats in making generalizations based on our results: first, the study group was small, and second, we do not know how the subjects who did not consent to participate in the study would have reported on their well-being. Based on clinical experience, patients who refuse to participate in rehabilitation - who would probably also refuse to be medically examined or interviewed for research purposes - have serious difficulties in adaptation to their injury, so it is possible that the good result of the present study is biased and the reality is not quite as positive.

Taken together, the results suggest that adults with pediatric spinal injury are psychologically well adjusted. Being symptom-free does not mean, however, that the adaptation process is completed: the underlying defensive functions seem to evolve at a pace of their own. This result is consistent with the notion of Trieschman ${ }^{8}$ that rehabilitation is a lifelong process of learning.

\section{References}

1 Fullerton DT, Harvey RF, Klein MH, Howell TH. Psychiatric disorders in patients with spinal cord injury. Arch Gen Psychiatry 1981; 38: $1361-1371$.

2 Craig AR, Hancock KM, Dickson HG. A longitudinal investigation into anxiety and depression in the first 2 years following spinal cord injury. Paraplegia 1994; 32: 675-679.

3 Trieschman RB. The psychosocial adjustment to spinal cord injury. In: Bloch RF, Basbaum M, (eds). Management of Spinal Cord Injuries 1986; Williams and Wilkins, Baltimore.

4 Richards JS. Psychologic adaptation to spinal cord injury during first postdischarge year. Arch Phys Med Rehabil 1986; 67: $362-$ 365.

5 Vaillant G. Ego mechanisms of defense 1992; American Psychiatric Press, Washington DC.

6 Guttmann L. Spinal cord injuries-comprehensive management and research 1976; Blackwell Scientific Publications, Oxford, London, Edinburgh, Melbourne.

7 Bracken MB, Shephard MJ. Coping and adaptation following acute spinal cord injury: a theoretical analysis. Paraplegia 1980; 18: $74-85$.

8 Trieschman RB. Spinal Cord Injuries: psychological, social and vocational adjustment 1980; Pergamon Press, New York.

9 Goldberg D. The detection of psychiatric illness by questionnaire 1972; Maudsley Monographs 21, New York.

10 Derogatis LR. SCL-90 Administration, scoring and procedures manual-II 1983; Clinical Psychometric Research, Towson.

11 Bond M, Gardner ST, Christian J, Sigal JJ. Empirical study of self-rated defense styles. Arch Gen Psych 1983; 40: 333-338.

12 Andrews G, Singh M, Bond M. The Defense Style Questionnaire. J Nerv Ment Dis 1993; 181: 246-256.

13 Mehnert T. Correlates of life satisfaction in those with disabling conditions. Rehabilitation Psychology 1990; 35(1): 3-17.

14 Cushman LA. Spinal cord injury: 10 and 15 years after. Paraplegia 1992; 30: 690-696.

15 Siosteen A, Lundqvist C, Blomstrand C, Sullivan M. The quality of life of three functional spinal cord injury subgroups in a Swedish community. Paraplegia 1990; 28: 476-488. 